\title{
Diagnostic Algorithm for Proper Selection of Patients Undergoing Endoscopic Dacryocysto rhino stomy
}

\author{
WAEL A. ALZAMIL, M.D.* and MOHAMMAD A. ALZAMIL, M.Sc.** \\ The Departments of Otorhinolaryngology, Hearing \& Speech Institute* and Ophthalmology, 6 th October University Hospital**
}

\begin{abstract}
Background: Increased lacrimation or tearing is considered a symptom of a large number of pathologies and differential diagnoses. It may be due to increased lacrimal outflow as a result of infection, allergy, and trauma, or may be due to defective drainage function of the lacrimal system resulting in epiphora (1). Defective drainage function may be due to obstruction or stenosis at any level of the drainage system, or may be due to week apposition of the lacrimal puncti on the eye globe like patients with ectropion due to scarring or muscle weakness in which the lid gets outwards eversion, a condition that is called ectropion. This condition can be caused by various etiologies, the most important of which are tractional by scarring or paretic by facial paralysis or senile atrophy (2). So proper identification of the nature of tearing (lacrimation or epiphora) and the level of obstructed drainage is of paramount importance to target our management or surgical approach and to obtain higher success rates, less failures and minimal recurrences (3). Depending upon the level of the obstruction, specific surgical procedures were used. These may include any of the following procedures, punctual dilatation, punctoplasty, Canalicular reconstruction, Canaliculodacryocystorhinostomy, Close dacryointubation, dacryocystorhinostomy (External and Endoscopic), Conjunctivo dacryocystorhinostomy and Dacryocystectomy etc (4). Endoscopic dacryocystorhinostomy is considered an effective and safe approach addressing obstructive etiology of epiphora other than punctual pathologies (5). So proper preoperative diagnostic work at various levels (history, examination and investigations) is essential for successful management.
\end{abstract}

Aim of Study: 1- The first aim of our study is to construct a diagnostic algorithm and management plan for patients with obstructive lacrimal pathology and epiphora. 2- To evaluate this Algorithm as regards the surgical outcome of endoscopic dacryocystorhinostomy.

Patients and Methods: A prospective, study conducted from September 2015 to December 2020 on 20 patients suffering increased lacrimation. Patients have been subjected to special stepwise diagnostic algorithm and classified into three main groups $\mathrm{A}, \mathrm{B}$ and $\mathrm{C}$ according to the pathology and treatment plan. Group A of 11 patients suffering retro-punctual obstruction managed by endoscopic dacryocystorhinostomy while 5 patients in group B suffering punctual etiology (ob-

Correspondence to: Dr. Wael A. Alzamil, The Department of Otorhinolaryngology, Hearing \& Speech Institute struction and diversion or malposition) and 4 patients in group $\mathrm{C}$ suffering increased lacrimation rather than obstruction have been fulfilled the exclusion criteria and referred for proper ophthalmological management.

Results: In group A, 11 patients undergone the diagnostic algorithm and fulfilled the inclusion criteria of retro-punctual obstruction of the lacrimal drainage system. Patients in group A have been managed by endoscopic dacryocystorhinostomy except one infant patient. They were doing well throughout the follow up period (4-6 months). In the 10 operated patients and before silicon tube removal, 7 patients reported complete improvement of epiphora, 2 patients reported decreased epiphora and 1 patient has no change of epiphora. After stent removal all operated patients of group A (10) reported complete improvement of epiphora with no recurrence after 6 months. 5 Patients in group B suffering punctual etiology (obstruction and diversion) and 4 patients suffering increased lacrimation rather than obstruction have been referred for ophthalmologist and managed accordingly. They were doing well except two patients in group B suffering punctual stenosis and obstruction who needed repeated dilatations and one patient reported to be indicated for punctoplasty.

Conclusion: Application and following the diagnostic Algorithm steps and adhering to it have markedly improved patient selection and the final outcome of endoscopic dacryocystorhinostomy and effectively referred non obstructive or punctual patients for proper ophthalmologic management to avoid non indicated endoscopic dacryocystorhinostomy and treatment failure.

Key Words: Indicated dacryocystorhinostomy-Diagnostic Algorithm for DCR.

\section{Introduction}

THE lacrimal system is composed of two main components, The main and accessory lacrimal glands and the lacrimal excretory system. The lacrimal excretory or drainage system is divided into proximal and distal segments. The proximal segment includes the puncti, (superior and inferior punctum) the superior and inferior canaliculi, and the common canaliculus. The distal lacrimal drainage segment consists of the lacrimal sac and the nasolacrimal duct that opens under the inferior 
turbinate and empties into the inferior meatus inside nasal cavity. Blinking is important in dispersion of tears allover globe surface and in drainage mechanism into lacrimal system [6].

Tears are exocrine secretions of the lacrimal glands. They are essential part of the visual system that maintains normal visual function. Tear film is a thin layer (7-10 micrometers thick) which constantly covers corneal and conjunctival epithelium. It consists of three layers:

1- The outermost lipid layer.

2- The middle aqueous layer.

3- The innermost mucus layer.

Outer lipid layer is produced by Meibomian glands and glands of Zeis in lids, and its functions are to reduce evaporation of middle aqueous layer and lubricate lid movements on the globe. The middle aqueous layer which represents $90 \%$ of tear film is formed by the main and accessory lacrimal glands. It nourishes, moistens and washes away foreign particles or irritants. The inner mucinous layer is secreted by Goblet cells of the conjunctiva, and overlays the cornea evenly and for proper spreading of the aqueous components of tear film over the hydrophobic corneal epithelium. Other functions of tear film are to reduce growth of microorganisms by mechanical flushing and antimicrobial effect of lysozyme, gamma globulins. Also it produce smooth optical surface for the cornea by leveling out minimal superficial epithelial irregularities [6,7].

More than $90 \%$ of the lacrimal fluid is removed by the excretory system, whereas less than $10 \%$ evaporates between blinks. Outflow is mainly regulated by the pumping effect of the orbicularis oculi muscle (Horner muscle). Tears are thus drawn into the lacrimal excretory system after each blink. The passage of tears down the nasolacrimal duct is influenced by gravity, evaporation in the nose, during inspiration and expiration [7].

Obstruction of the lacrimal drainage system will lead to epiphora (tearing). According to the exact cause and location of the obstruction, specific surgical procedures are used. Also epiphora may be confused with excessive lacrimation caused by trauma, infection or allergy. So, epiphora as an obstructive drainage disease has huge number of etiologies affecting various levels of the lacrimal system. Also epiphora has huge number of differential diagnoses of non epiphora lacrimation caused by infection, allergy, mechanical or chemical trauma, glaucoma, migraine and trigeminal neuralgias etc [8]. Dealing with such symptom having huge number of obstructive and non-obstructive differential diagnoses should follow a systematic stepwise diagnostic workup to reach and clarify the exact diagnosis regarding nature of lacrimation (epiphora versus excess lacrimation) and the level of obstruction in epiphora patients. This systematic stepwise approach or algorithm aims primarily to manage the disease in a precise effective way avoiding non indicated surgeries and following strict inclusion and exclusion criteria [9]

Understanding the detailed anatomy and physiology of the lacrimal system is essential to tailor a plan of management or surgery. The lacrimal drainage pathway starts by the lacrimal punctum, then the canaliculi, nasolacrimal sac, and finally the nasolacrimal duct. The punctum is located on the lacrimal papillae, facing slightly towards the globe, on both the upper and lower lids. This small aperture of approximately $0.3 \mathrm{~mm}$ in its diameter allows proper flow of tears into the canaliculus. The upper and lower eyelids have one canaliculus each. These are lined with nonkeratinized squamous epithelium. The canaliculus initially travels about $2 \mathrm{~mm}$ vertically, and then turns horizontally in parallel with the eyelid margin [10]. The horizontal component of the canaliculus is surrounded by Horner's muscle, which is part of the lacrimal part of orbicularis oculi. Horner's muscle contributes to the lacrimal pump function, and any dysfunction of orbicularis oculi may contribute to epiphora due to pump failure. In most individuals (94\%), the canaliculi from the upper and lower lids converge and join to form the common canaliculus. The length of the upper canaliculus is about $8 \mathrm{~mm}$, whereas the lower canaliculus is about $10 \mathrm{~mm}$. The canaliculi angle slightly posteriorly, but the common canaliculus, in turn, may angle anteriorly. Awareness of this change in direction is essential for safe, atraumatic syringing and probing in the pre-operative assessment and intraoperative work [11]. The common canaliculus then pierces the periorbita and enters the lacrimal sac. However, in some individuals, separate upper and lower canaliculi may enter the sac. The entry into the lacrimal sac most often occurs obliquely, which forms the valve of Rosenmueller. It is not a true valve, but the angulation of the common canaliculus as it enters the sac prevents retrograde flux and acts in a valve-like manner [12]

The nasolacrimal sac and duct are continuous rather than separate structures that are lined with non-ciliated columnar epithelium. The sac lies within the lacrimal fossa, which is formed by the lacrimal bone and the frontal process of the maxilla. Its dimensions are 12 to $15 \mathrm{~mm}$ in height and 4 to 
$8 \mathrm{~mm}$ anteroposteriorly. The superior fundus of the sac extends 3 to $5 \mathrm{~mm}$ above the medial canthal tendon. The nasolacrimal duct extends inferolaterally and posteriorly through the bone for approximately $12 \mathrm{~mm}$, exiting underneath the inferior turbinate. This nasolacrimal duct ostium is located 25 to $30 \mathrm{~mm}$ posterior to the anterior nares. The exit of the nasolacrimal duct into the nose is can be round or slit-like and is protected by a mucous membrane covering, called the valve of Hasner or plica lacrimalis [13]

The lacrimal fossa is formed by the frontal process of the maxilla anteriorly and the lacrimal bone posteriorly. The fossa is bordered by the anterior lacrimal crest and posterior lacrimal crest. The lacrimal fossa measures about $16 \mathrm{~mm}$ vertically and 2 to $4 \mathrm{~mm}$ deep with a width of 7 to $10 \mathrm{~mm}$. Variability exists depending upon ethnic origins. The axilla of the middle turbinate marks the point of the middle turbinate inserting into the frontal process of the maxilla and tends to be a constant anatomical landmark. The lacrimal fossa is situated superiorly, anteriorly and laterally to the axilla of the middle turbinate $[\mathbf{9 , 1 3}]$

Dacryocystorhinostomy (DCR) describes the creation of a functional connection from the conjunctival sac into the nose through the natural lacrimal system by means of creating a persistent fistula between the lacrimal sac and nasal cavity provided that the upper lacrimal system is patent (punctum and canaliculi). This connection is accomplished via an osteotomy in the lacrimal bone and opening the nasolacrimal sac into the nose. It can be performed via an external or endonasal approach [14]. Endoscopic dacryocystorhinostomy is considered now the standard, effective and safe procedure for patients with obstructive retropunctual epiphora and some resistant cases of punctual etiology which may have additional distal lacrimal obstruction. The effectiveness of this procedure may be $100 \%$ if it manage patients with proper inclusion criteria leaving others with exclusion criteria for proper ophthalmological management to obtain the best final outcome [15]. Inclusion and exclusion criteria can be collected by a precise systematic approach to reach the exact diagnosis and categorize patients for their specific treatment modality. In our study we have constructed a diagnostic approach or algorithm (Diagram 1) to select patients who will benefit from endoscopic dacryocystorhinostomy and pick other patients with similar symptoms who are not indicated for endoscopic dacryocystorhinostomy to be managed accordingly in a proper manner.

\section{Patients and Methods}

Ethics:

The ethics committee of our institution approved this work according to the Declaration of Helsinki. A detailed informed consent was obtained from each patient.

A prospective, study conducted from September 2015 to December 2020 on 20 patients suffering increased lacrimation. Patients have been subjected to special stepwise diagnostic algorithm and classified into three main groups $\mathrm{A}, \mathrm{B}$ and $\mathrm{C}$ according to the pathology and treatment plan. Group A of 11 patients suffering retro-punctual obstruction managed by endoscopic dacryocystorhinostomy while 5 patients in group B suffering punctual etiology (obstruction and diversion) and 4 patients in group $\mathrm{C}$ suffering increased lacrimation rather than obstruction have been fulfilled the exclusion criteria and referred for proper ophthalmological management. Endoscopic dacryocystrhinostomy and silicone tube stenting was done for two resistant patients in group B after performing CT scanning which was negative regarding chronic dacryocystitis.

Diagnostic Algorithm of the study consists of the following steps (Diagram 1):

1- Complete detailed history which can reach the final diagnosis in some patients even before examination and investigations. Starting by the personal history, age of the patient can point to congenital nasolacrimal stenosis or obstruction with early onset after birth and early infancy (group A). Middle aged females showed increased incidence of chronic dacryocystitis and retro-punctual lacrimal drainage obstruction and epiphora (group A). Elderly patients may suffer epiphora due to ectropion of the lower eye lid with muscle weakness and laxity rather than obstruction to be excluded from dacryocystorhinostomy procedures (group B). Occupations associated with chemical pollution exposure or dust can predispose to foreign bodies or allergic reactions like conjunctivitis and allergic rhino sinusitis with increased lacrimal secretions rather than epiphora to be excluded again from dacryocystorhinostomy (group C). Special habits such as smoking or addiction also predispose to allergic reactions or chemical irritation leading to increased lacrimation (group C). Also may be associated with chronic dacryocystitis (group A).

Stressing on the complaint regarding its onset, course and duration can differentiate and help to reach a diagnosis. Also severity and laterality (bilateral or unilateral) add more information. 
Using uniform grading system such as the Munk scale Table (1) is helpful in assessing severity. For example, allergic and inflammatory eye diseases usually present with bilateral affection with short durations and intermittent or remittent course of increased lacrimation and running nose, itching or sneezing related to allergen exposure (group C). Whoever, unilateral insidious onset, long duration and continuous coarse points to epiphora with obstructive etiology (group A). History of medial eye lid pain and swelling or purulent discharge can diagnose chronic and acute dacryocystitis (group A). History of eye lid trauma or surgery may reflect the possibility of ecropion, scaring or punctual affection (group B). Recent history of facial paralysis can lead to more eye exposure and irritation due to weak infrequent blinking and incomplete eye closure. This irritation will result in increased reflex lacrimation rather than baseline lacrimation which is usually reduced in facial paralysis (group C). Also weak or paralyzed redundant lower eye lid will interfere with punctum contact to eye globe (group B). Past history of nasal disease (scleroma or polyposis) or surgery associated with unilateral eye tearing may confirm nasolacrimal obstruction (group A). Also history of maxillofacial traumas or fractures may lead to nasolacrimal obstruction (group A) or scaring and ectropion of the lower eye lid (group B).

2- Examination of the patients was done to confirm the expected diagnosis from history. General and local examination to pick up sings of allergy, cornea foreign body or traumatic corneal ulcer (group C). Confirming the presence of ectropion and scarring (group B) or local swellings, abscesses or purulent discharge with evidence of infection and obstruction (group A). Local swelling and tenderness over the lacrimal bone raising the evidence of chronic dacryocystitis with abscess or mucocel formation (group A). Slit lamp examination as an essential part of ophthalmic examination done to confirm or exclude punctual pathology (group B). We recognize the papilla, presence of a membrane or fibrosis over the punctum, punctum size, tear meniscus height, eyelid margin, conjunctiva around the punctum, malposition, position of the punctum in the tear lake, and any sign of previous surgery and to rule out any associated ocular surface abnormalities.

\section{Specialized examination:}

3- Regurge test in which we apply gentle massage over the medial canthus either normal appearance or swollen to express purulence or mucopus confirming chronic dacryocystitis (group A).
4- Fluorescein instillation Test done in two forms. The first form performed by the ophthalmologist coauthor for detecting dye disappearance (abnormal dye disappearance test) and to assess abnormal tear drainage system. It is noninvasive, relatively objective and quantitative test and useful for patients with poor compliance, including infants instilling fluorescein sodium dye $0.25 \%$ into the lower lid cul-de-sac. The dye should drain properly and disappear through the lacrimal excretory system after approximately five minutes, indicating a negative (i.e., normal) result. If drainage is absent or prolonged more than five minutes, so there may be punctual or retro punctual obstruction or stenosis (group B or group A).

The second form of the test was done by the otorhinolaryngologist coauthor by adding to the previous steps insertion of dry cotton pledges in the inferior meatus bilaterally even in unilateral presentations to compare both sides. We advise patient to blink frequently for pumping action of Horner muscle. After five minutes we remove the cotton pledges for inspection of staining. If there no fluorescein stain, the test is positive for obstruction or stenosis (group A or B).

5- Schirmer 2 test. In Schirmer 2 test we add local anaesthetic eye drops to inhibit reflex tearing which may be due to foreign body irritation or rubbing eye lash (in contrast to schirmer 1 which is a test to diagnose dry eye). In both tests we place a piece of filter paper inside the lower eyelid of both eyes and the patient closes his/her eyes. After 5 minutes, we remove the filter paper and observe the wet segment in the paper or compare both eyes or compare the result of Schirmer 1 and 2 (before and after local anaesthetic application). If there is difference between Schirmer 1 and 2, this means that the eye which has more lacrimal flow is abnormal and has reflex hyper lacrimation due to irritation (group C) such as foreign body, rubbing eye lash or corneal ulcer. So this result will exclude epiphora.

6- Local anesthetic eye drops application which is more simple than Schirmer test and has the same principles but without filter paper.

Nasal examination by anterior rhinoscopy and Hopkin's rod endoscopy to role out swellings, adhesions and fibrosis such as scleroma patients or post traumatic and post-surgical adhesions leading to low nasolacrimal system obstruction (group A). 
7- Investigations: CT scan paranasal sinuses bone window axial and coronal cuts was very useful and informative in all cases. CT findings have augmented the diagnosis of chronic dacryocystitis (group A) by showing soft tissue opacification and evidence of dilatation due to mucocel or abscess formation in the lacrimal drainage system (Figs. 1,2).

After performing the previously mentioned steps, the 20 patients of the study have been divided into three main groups.

Group A of 11 patients suffering retro-punctual obstruction or obstructed lacrimal drainage with normal punctum. Among 11 patients of the group there were two infants under 2 years age, one child 5 years old and 8 adult patients. Regarding six distribution, there were 9 females and 2 males. The 11 patients with obstructive epiphora have presented bilateral disease in 7 patients and unilateral in 4 patients. Two patients were suffering rhinoscleroma in their atrophic and fibrotic stage. Two patients in the group having past history of lacrimal surgery and one patient undergone repeated probing but with rapid recurrence of symptoms. Two females of this group suffered allergic sinonasal polyposis and presented with bilateral epiphora. This group showed positive fluorescein test with absent dye drainage in 8 patients and sluggish drainage in three patients. Slit lamp examination has excluded punctual pathology in this group. Positive regurge test was positive in three unilateral patients with pus coming out the punctum by palpation and massage over the medial canthus. CT scan axial and coronal cuts showed evidence of chronic dacryocystitis with soft tissue opacification and evidence of expansion or mucocel formation in 6 patients (4 bilateral and 2 unilateral). Ten patients of this group have been managed by endoscopic dacryocystorhinostomy while one infant patient was subjected to conservative treatment and follow-up.

Group B contains 5 patients who have punctual etiology. The first patient is 1.5 years old with history of unilateral epiphora since birth with slit lamp evidence of obstruction. Three patients of this group were 2 adult middle age females ( 1 bilateral and 1 unilateral) and one bilateral 10 years old child with slit lamp evidence of obstruction and stenosis and negative regurge test. The last patient in this group was an elderly male patient with bilateral epiphora and slit lamp evidence of bilateral lower lid laxity and mild ectropion. Fluorescein test was positive in all patients with prolongation of drainage more than 5 minutes in one unilateral adult patient and absent in four patients. CT scanning was postponed in this group to fulfill ophthalmological management in the form of propping and frequent punctual dilatation or lid surgery for ectropion. CT scanning and endoscopic dacryocystrhinostomy were considered for any patient in this group not responding to ophthalmological management. Endoscopic dacryocystrhinostomy and silicone tube stenting was done for two resistant patients ( 2 adult females) after performing CT scanning which was negative regarding chronic dacryocystitis. The 10 years child (Fig. 3) has history of three revision surgeries (DCR) with rapid recurrences. He was a candidate for punctoplasty or conjunctivodacryocystorhinostomy.

Group C of four patients suffering increased lacrimation rather than obstruction as proved from history being bilateral intermittent sever lacrimation associated with allergen exposure and other allergic manifestations such as sneezing, rhinorrhea and itching. Fluorescein test was done to confirm patency (negative result). Slit lamp examination, and CT scanning were not done. Schirmer 2 test and local anesthetic eye drop test was done and showed unilateral increased reflex lacrimation in two patients of the group. For those two patients, Slit lamp examination has confirmed the presence of rubbing eye lashes in one patient and traumatic corneal ulcer in the other patient. Those patients have been fulfilled the exclusion criteria regarding endoscopic DCR and referred for proper ophthalmological medical treatment.

\section{Operative procedure:}

Endoscopic dacryocystrhinostomy and silicon tube stenting was performed for 10 patients in group A (excluding infant patient) and two resistant patients in group B. Under general hypotensive endotracheal anesthesia with the patient in supine position, head elevated and tilted to the right, decongestant nasal packing was done. After 5 minutes, nasal pack was removed and full endoscopic assessment of the nasal cavity was performed again with relaxed anesthetized patient. Local infiltration was done just anterior to the anterior end of the middle turbinate over the lacrimal bone injecting xylocain with $1 / 20000$ adrenaline. After three minutes of injection I started making mucosal flaps over the lacrimal bone by doing vertical incision by the sickle knife, reducing the size of flaps by thru cutting forward or up biting forceps to expose the lacrimal bone. Starting drilling the hard lacrimal bone by three mms cutting burr with copious irrigation and suction to expose the wall of lacrimal sac. Now, I perform fluctuation test to 
confirm proper access to the lacrimal sac. This test was done by performing gentle repeated pressure over the ipsilateral medial canthus and observe the transmitted pulse in the sac. If there is no transmitted pulse, I may have my opening more anterior to be in the subcutaneous tissues or more posterior. So I should revise my orientation. After identification of the lacrimal sac, I incise it vertically by the sickle knife to reach its lumen. Now I will shift to eye lid work. I can identify the upper and lower puncti (better with magnifying loop) and start to probe each punctum with dilators of increasing size. I pass the dilators into the upper and lower canaliculi respectively to reach the lacrimal sac respecting their directions (Fig. 4). Then I try to find the dilator in the nose and withdraw it through the opened lacrimal sac. The main aim of this maneuver is to dilate the punctual and canalicular ducts to facilitate the next step. My next step, I start to insert the silicon tube by passing the metal wire into the punctum down to the lacrimal sac and then pulling it nasally through the incised sac. Repeating this maneuver in the other punctum to obtain a small silicone loop between the puncti. I then remove the two metal wires nasally and ligate the silicone tube ends making a knob in the nasal cavity and cut the excess silicon tube length.

Intraoperative fluorescein test was done in all cases to confirm proper drainage. I have instilled drops of fluorescein dye in the ipsilateral eye and after gentle massage over the medial canthus I observe its passage through the incised sac endoscopically.

These steps were repeated in the other eye in bilateral cases. Lastly, nasal packing was done by $8 \mathrm{cmms}$ merocel pack soaked with antibiotic ointment and then swollen by decongestant saline solution.

Nasal packs were removed after 48 hours. Regular follow-up visits every 2 weeks for 1.5 months and then monthly for four to six months was done. Silicone tube has been removed after 4 to 6 months in the outpatient clinic by cutting the silicone loop first between the upper and lower punctum and then withdrawal of the silicone knob nasally.

Data were collected from intraoperative findings and postoperative follow-up and tabulated for result recording.

\section{Results}

The average age of patients in group A was $25.0 \pm 2.5$ years, whereas that in group B was $22.5 \pm$
3.25 years. In group $C$ The average age of patients was $32.0 \pm 1.75$. The study population comprised 6 male patients (30\%) and 14 female patients (70\%).

During the follow-up period for all patient groups an assessment and recording were done regarding improvement of symptoms, recurrence or complications. Also the final outcome for all groups was recorded after six months.

In group $\mathrm{A}, 11$ patients undergone the diagnostic algorithm and fulfilled the inclusion criteria of retro-punctual obstruction of the lacrimal drainage system. 10 patients in group A have been managed by endoscopic dacryocystorhinostomy excluding one infant patient. They were doing well throughout the follow-up period of 4 months. In the 10 operated patients and before silicon tube removal, 7 patients reported complete improvement of epiphora, 2 patients reported decreased epiphora and 1 patient has no change of epiphora. After 4 months, stent was removed and all operated patients of the group were observed and followed for additional two months. They reported complete improvement of epiphora with no recurrence.

In group B, 5 patients were suffering epiphora due to punctual etiology (obstruction and diversion). The first infant patient 1.5 years old responded well to conservative management in the form of frequent massage and follow up. Three patients of this group were adult middle age females ( 2 bilateral and 1 unilateral) with slit lamp evidence of obstruction and stenosis and negative regurge test. Those patients were managed by propping and frequent punctual dilatation. Only one patient has responded satisfactorily with complete improvement of epiphora whoever two patients showed recurrence of symptoms during the follow-up period. The recurrent cases have been managed by Endoscopic dacryocystrhinostomy. They were followed for additional six months and showed satisfactory improvement with disappearance of epiphora during and after silicon tube removal. The last patient in this group was an elderly male patient with bilateral epiphora and slit lamp evidence of bilateral lower lid laxity and mild ectropion. This patient showed moderate cessation of epiphora after conservative management in the form of repeated lid exercises, nutritional and general body support.

In group $C$ there are 4 patients suffering increased lacrimation rather than obstruction. Two of them (bilateral lacrimation) who were diagnosed as allergic conjunctivitis and allergic rhinosinusitis showed rapid and complete improvement with 
systemic and local anti-allergic measures in the form of steroids, antihistaminics and mast cell stabilizers. Those two patients suffered full and partial recurrences during the follow-up after cessation of treatment or exposure to allergen or pollution. The other two patients (unilateral lacrimation) were suffering traumatic irritation due to rubbing eye lashes in one patient and traumatic corneal ulcer in the other. They have complete cure after definitive management for their pathology.

Table (1).

\begin{tabular}{cl}
\cline { 2 - 2 } Grade & Munk scale \\
\hline 0 & No epiphora \\
1 & Epiphora requiring dabbing less than twice \\
& a day \\
2 & Epiphora requiring dabbing 2-4 times a day \\
3 & Eppiphora requiring dabbing 5-10 times a day \\
4 & Epiphora requiring dabbing more than 10 times \\
& a day \\
5 & Constant epiphora \\
\hline
\end{tabular}

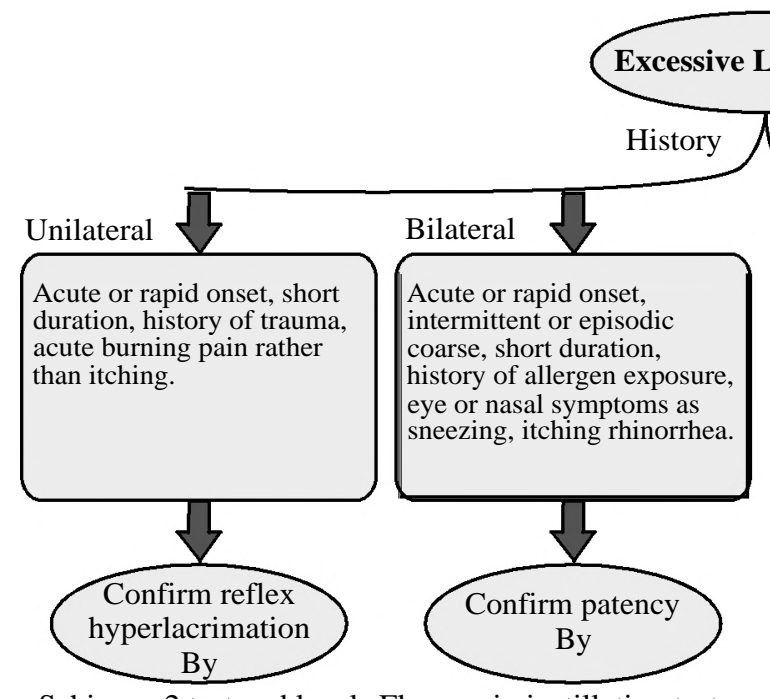

Schirmer 2 test and local Flourecein instillation test anesthetic eye drop test

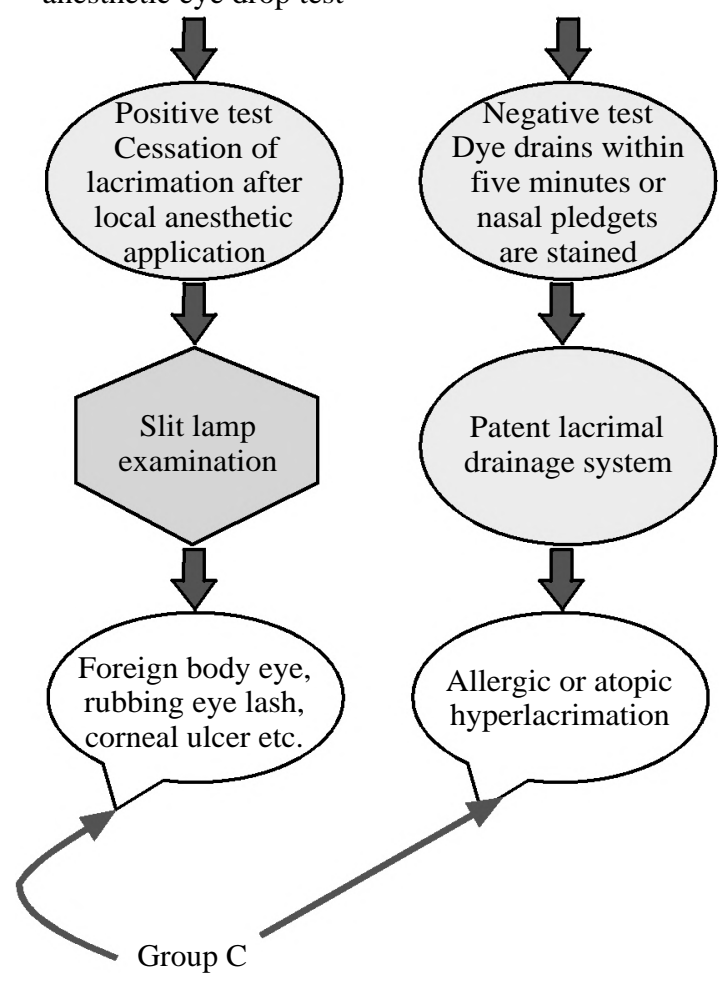

\section{Taking}

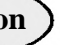
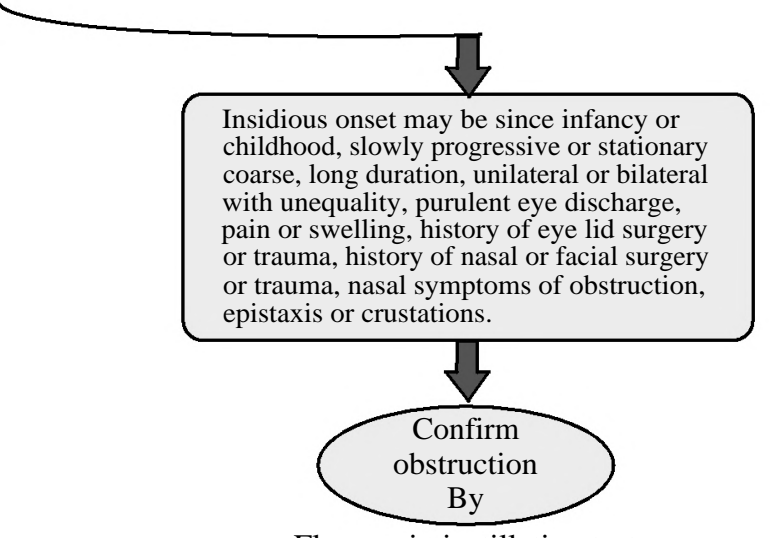

Flourecein instillation test

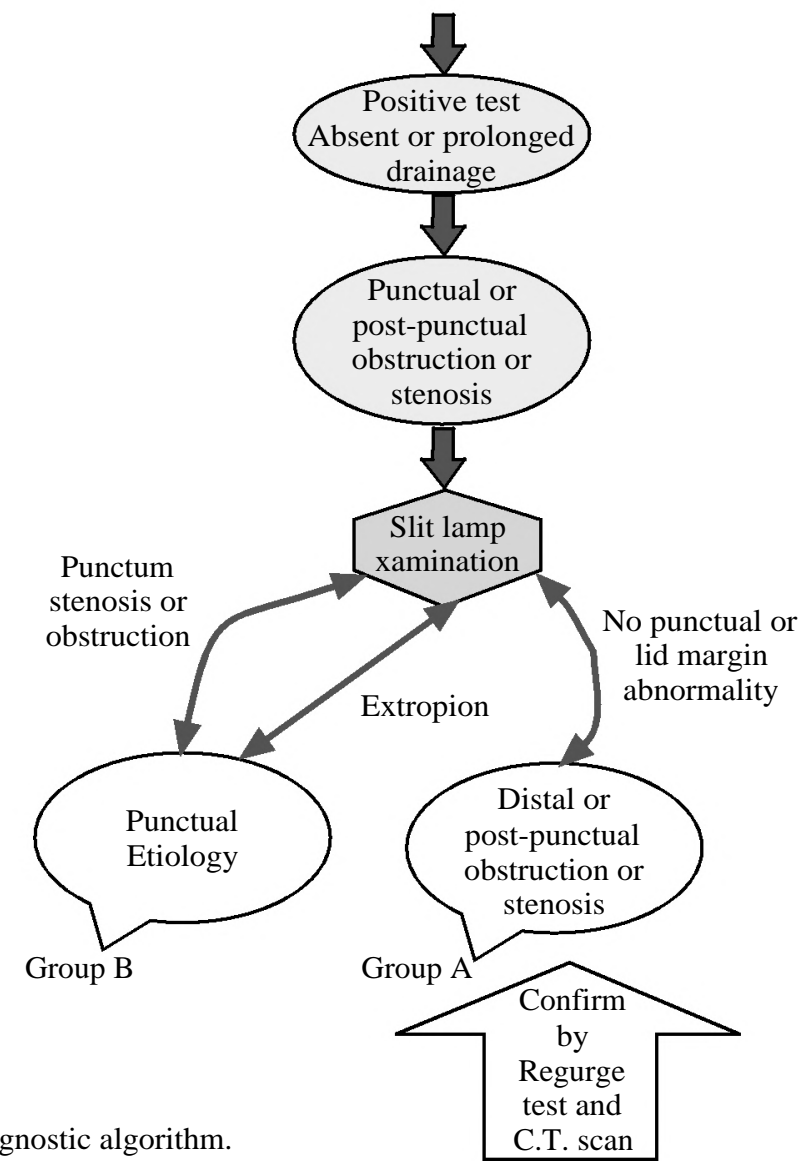

Diagram (1): Diagnostic algorithm. 


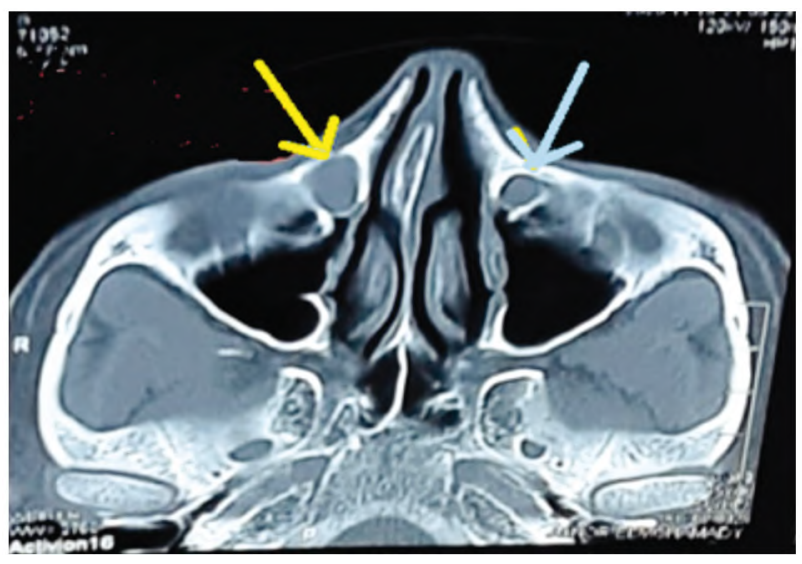

Fig. (1): C.T. axial cuts showing dilated right lacrimal sac (yellow arrow) in contrast to normal left sac (blue arrow).

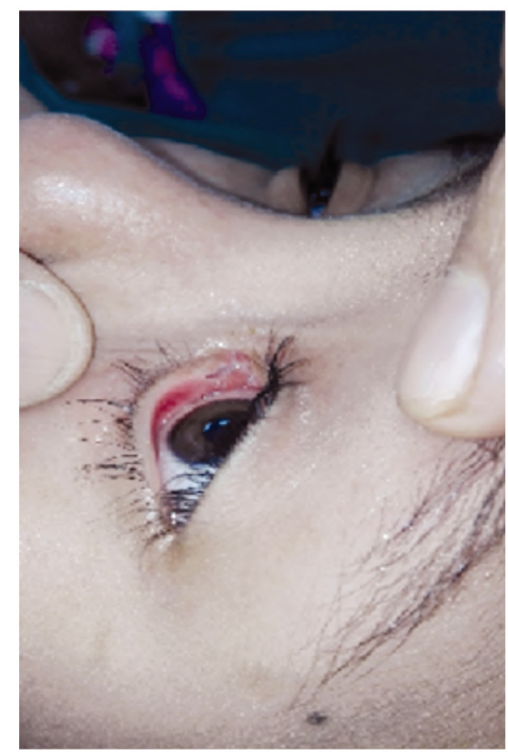

Fig. (3): Distroyed lower punctum after failed three surgeries.

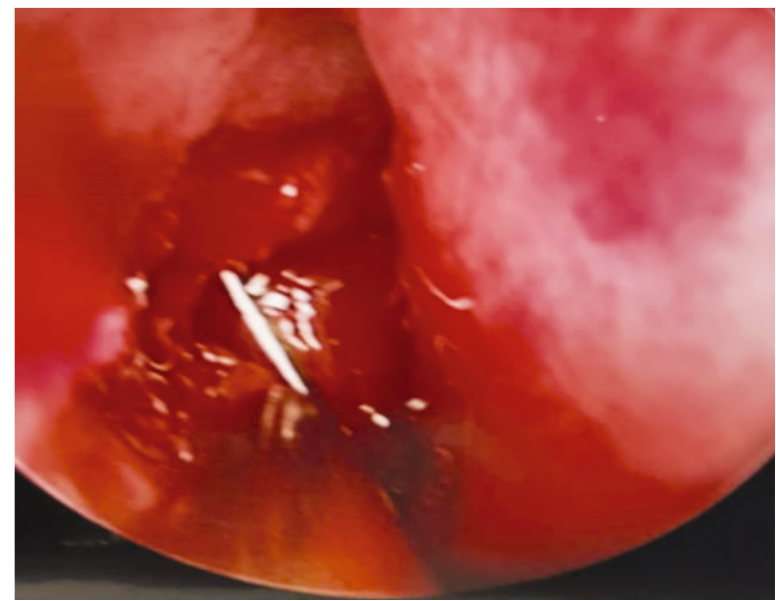

Fig. (5): Getting the lacrimal probe from the nasal side.

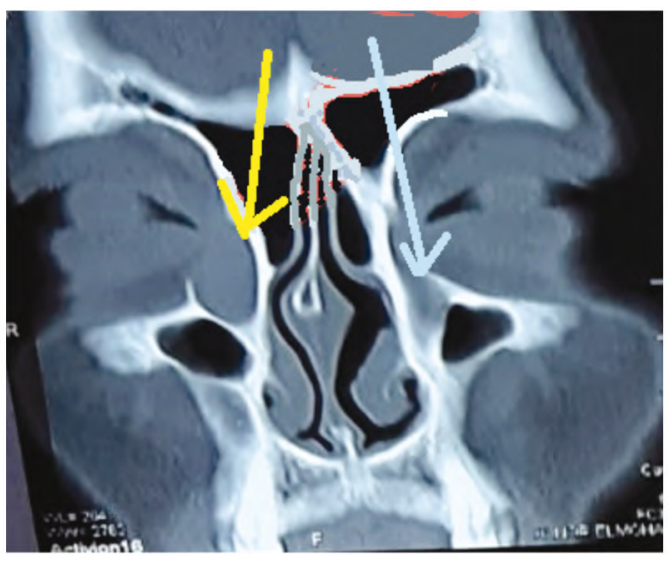

Fig. (2): C.T. scan coronal cuts showing dilated right lacrimal sac (yellow arrow) in contrast to left normal sac (blue arrow).

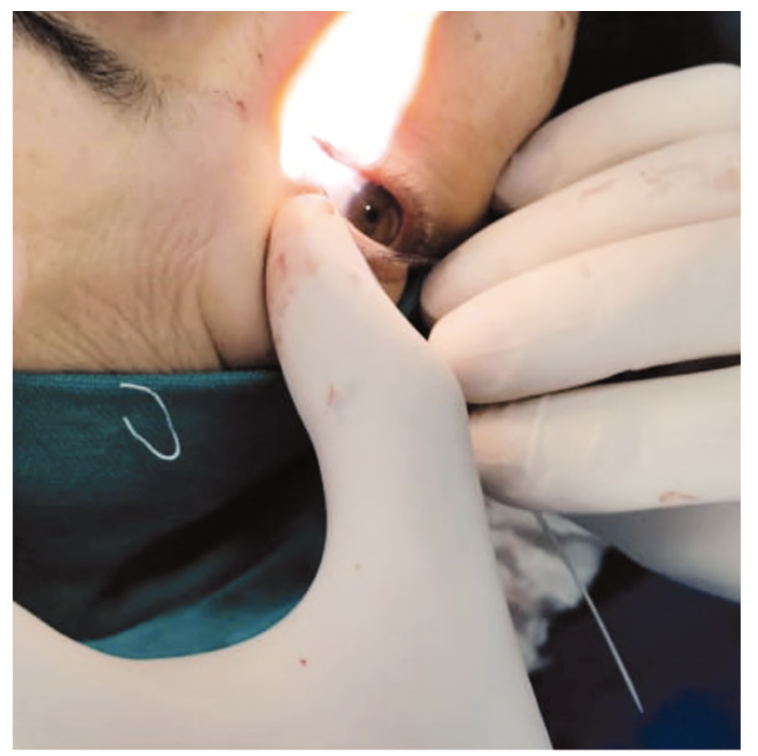

Fig. (4): Probing the lower punctum.

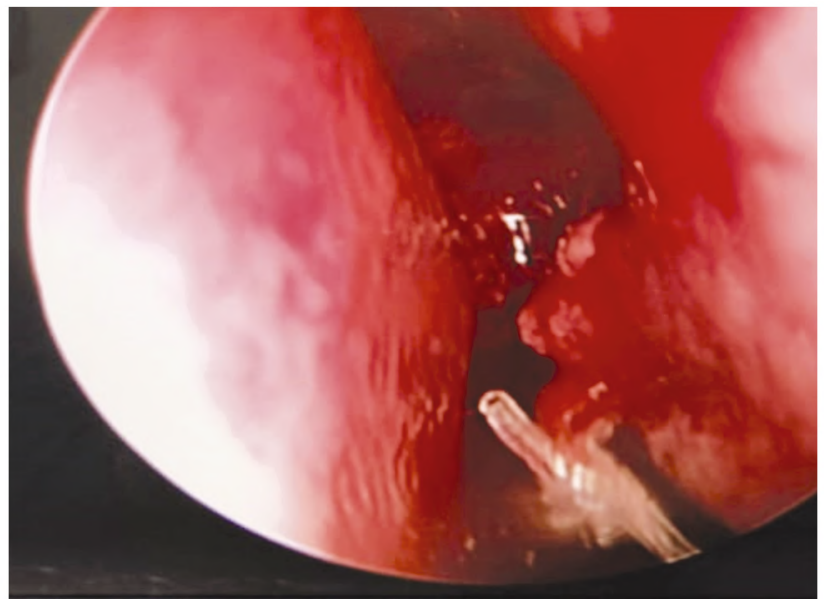

Fig. (6): Endoscopic view of the silicon knot. 


\section{Discussion}

Before selecting patients for endoscopic dacryocystorhinostomy, there are two main objectives. The first objective is proper understanding about the surgical technique regarding its historical background, anatomical and physiological bases. The second objective is the criteria of selection in those patients with similar symptoms but having different underlying pathologies regarding the nature of lacrimation (epiphora versus hyper lacrimation) and the level of obstruction.

The aim of performing a dacryocystorhinostomy is to create a fistula between the nasolacrimal sac and the nose, thus bypassing any obstruction and allowing passage of tears directly into the nose. The currently accepted technique of externalapproach dacryocystorhinostomy (DCR) was first described at the beginning of the 20 th century by the Florentine professor of otolaryngology, Addeo Toti in 1904 in the Italian literature, and later modified by Dupuy-Dutemps and Bourguet [16]

Historically the 12 th-Century Andalusian oculist Muhamad Ibn Aslam Al Ghafiqi described the principles of lacrimal surgery in his book "The Right Guide to Ophthalmology". He reported using a small spear-shaped instrument perforating the lacrimal bone in a nasal direction to create a fistula from the conjunctival fornix into the nose with secondary granulation and epithelialization. Indeed, this principle of fistulization remains the same to date as that of contemporary conjunctivodacryocystorhinostomy [17]

Toti's procedure exposed the lacrimal sac via an external incision. He then excised the medial wall of the lacrimal sac and removed the adjoining lacrimal and maxillary bone, together with the mucosa: He achieved this with a hammer and chisel. The skin incision was then closed. Toti modified the procedure in some cases with the removal of a portion of the middle turbinate and made wider bony windows. Kuhnt in 1914 introduced the suturing of the nasal mucosal flaps to the periosteum to reduce granulation tissue. DupuyDutemps and Bourget modified Toti's operation in 1921 with vertical incisions in the nasal mucosa and the lacrimal sac together with horizontal incisions at the top and bottom ends of the vertical incisions, thereby creating "book-openings". They sutured both the anterior and posterior flaps of the nasal mucosa and the lacrimal sac. In 1933, they further modified their technique by incising the fistula created and probed the passage repeatedly via the lower punctum to reduce granulation and scar tissue and obtained a success rate of $95 \%$ in 1000 cases. Ohm, in 1962, essentially described a procedure very similar to the one described by Dupuy-Dutemps and Bourget and sutured the nasal mucosa to the lacrimal sac [17].

Endonasal DCR was first described by Caldwell in 1893, who used an endonasal electric burr to remove bone once a metal probe had been passed through the canaliculus and into the lacrimal sac. Difficulties included adequate visualization, bleeding, accurate bone, and soft tissue removal. The technique was later modified by West in 1910 and Halle in 1914. Real endonasal surgical maneuver started with the rigid nasal endoscopes, which opened the way for advances in the field of endoscopic DCR. The modern-day approach to endonasal dacryocystorhinostomy was first reported by McDonogh and Meiring in 1989. It now being accepted as an effective approach to DCR in the management of epiphora due to nasolacrimal duct obstruction [18]

Regarding patient selection, there may be a dilemma among many patients having nearly the same complaint of increased lacrimation but they are suffering different diseases. Also more difficulty may be encountered when there are combinations of different pathologies or there is obstruction in multiple levels in the lacrimal excretory system. The later possibility may explain what happened with the two punctual patients in group B who showed recurrence after propping and dilatation but gained satisfactory improvement after endoscopic DCR.

Collecting information and positive data should be in a precise systematic way starting by the history taking passing through patient examination (locally and by specific tests) and ending by investigations. This stepwise workup should be in a smart Algorithm like manner to save time and effort in patient selection with minimal or absent bias.

In our study, we have constructed a Diagnostic Algorithm (Diagram 1) among 20 patients included in the study. By this algorithm the 20 patients have been classified into three groups A,B and C according the underlying pathologies regarding the nature of lacrimation (epiphora or hyper lacrimation) and the level of obstruction. Group A of 11 patients suffering retro-punctual obstruction managed while 5 patients in group B suffering punctual etiology (obstruction and diversion) and 4 patients in group C suffering increased lacrimation rather than obstruction. Of course the groups are not equal be- 
cause our study is not a comparative one and the effectiveness of a specific surgical procedure is not the scoop of our study. Whoever, we show the improved effectiveness of multiple procedures and maneuvers attacking different pathologies provided there is good patient selection for each procedure. Different procedures and modalities are innumerable including endoscopic DCR, propping and dilatation, punctual surgery, medications for allergy, surgery for ecropion, etc. whoever endoscopic dacryocystorhinostomy as a modality of treatment was discussed in more details in our study for two reasons, the first one is being the most used modality in the study (12 patients out of 20). The second reason is to emphasize certain critical aspects in the procedure which make it more safe and effective.

Looking for the diagnostic algorithm (Diagram, 1) if the history gives rapid or sudden onset of unilateral lacrimation, short duration, history of recent trauma with pain rather than itching, so the most possible diagnosis is reflex hyper lacrimation due to foreign body or corneal ulcer. We proceed directly to Schirmer 2 test or local anesthetic test to confirm and then we perform slit lamp examination to identify the exact pathology (foreign body, rubbing eye lash or corneal ulcer). Whoever if there is rapid onset of bilateral lacrimation, intermittent or episodic coarse, short duration and itching or other eye or nasal allergic symptoms such as sneezing or running nose and recent allergen or pollution exposure, we should suspect allergic hyper lacrimation (e.g, allergic conjunctivitis). We proceed directly to confirm patency of the lacrimal drainage system by fluorescein instillation test which will give negative result by disappearance of the dye within 5 minutes or dye staining of the nasal cotton pledges. Those patients with traumatic or allergic hyper lacrimation will be included in group $\mathrm{C}$ to be excluded from endoscopic DCR and should be directed for their specific treatment.

On the other side of the diagram, if there is a history of slowly progressive or stationary coarse of bilateral or unilateral lacrimation with insidious onset and long duration, also if there is purulent eye discharge, pain or swelling we may strongly suspect obstructive epiphora. That is true again with history of nasal or facial surgery or trauma or eye lid surgery or trauma with nasal symptoms of obstruction or bleeding. Now we proceed to perform fluorescein instillation test to confirm obstructed drainage system by obtaining positive test in which drainage is absent or prolonged more than five minutes, so there may be punctual or retro punctual obstruction or stenosis (group B or group A). The next step is slit lamp examination to detect punctual obstruction or stenosis and to exclude lid margin abnormalities such as scarring, laxity or ectropion. If these findings were detected by slit lamp examination, patients will be included in group B of punctual obstructive epiphora whoever if the examination excluded these findings the patients will be included in group A suffering retro punctual or distal lacrimal pathology. The next step is an optional one by performing regurge test and C.T. scanning for paranasal sinuses and lacrimal sac in an axial and coronal cuts utilizing bone and soft tissue window. These last two steps are positive in some cases of chronic dacryocystitis in which we may express pus or mucopus from the puncti by applying pressure on the medial canthus plus the C.T. evidence of lacrimal mucocel with bone expansion. Patients in group A are good candidates for endoscopic DCR. Also some patients in group B who get recurrences will undergo endoscopic DCR anticipating multiple level obstruction.

\section{Conclusion:}

By using the diagnostic Algorithm steps we have markedly improved our patient selection and the final outcome of endoscopic dacryocystorhinostomy and other treatment modalities by effectively referring non epiphora patients and punctual obstructive patients for proper ophthalmologic management to avoid non indicated endoscopic dacryocystorhinostomy and treatment failure.

\section{Financial support and sponsorship:}

Nil.

\section{Conflicts of interest:}

There are no conflicts of interest.

\section{References}

1- KUMAR S., MISHRA A.K., SETHI A., MALLICK A., MAGGON N. and SHARMA H.: Gupta, Comparing Outcomes of the Standard Technique of Endoscopic DCR with Its Modifications: A Retrospective Analysis. A. Otolaryngol. Head Neck Surg. Feb., 160 (2): 347-354, 2019.

2- ANSARI Z., SINGH R., ALABIAD C. and GALOR A.: Prevalence, risk factors, and morbidity of eye lid laxity in a veteran population. Cornea, 34 (1): 32-36, 2015

3- BLACKMORE K.J., AINSWORTH G. and ROBSON A.K.: Epiphora: An evidence based approach to the 12 minute consultation. Clin. Otolaryngol., 35 (3): 210-214, 2010.

4- KSHIRSAGAR R.S., VU P.Q. and LIANG J.: Orbit. Endoscopic versus external dacryocystorhinostomy: Temporal and regional trends in the United States Medicare population. Dec., 38 (6): 453-460, 2019. 
5- ULLRICH K., MALHOTRA R. and PATEL B.C.: Dacryocystorhinostomy. In: StatPearls [Internet]. Treasure Island (FL): StatPearls Publishing, Jan-Feb. 25, 2021.

6- RAJAK S.N. and PSALTIS A.J.: Anatomical considerations in endoscopic lacrimal surgery. Ann. Anat. Jul., 224: 28-32, 2019.

7- TSUBOTA K.: Tear dynamics and dry eye. Prog Retin Eye Res., 17 (4): 565-596, 1998.

8- WILLIAMS B., JOHNSON D., HURST J. and KRATKY V.: Patterns and causes of epiphora referrals to a tertiary oculoplastic practice. Can. J. Ophthalmol., 49 (2): 180$182,2014$.

9- NEMET A.Y.: The etiology of epiphora: A multifactorial issue. Semin Ophthalmol., 31 (3): 275-279, 2016.

10- GROESSL S.A., SIRES B.S. and LEMKE B.N.: An anatomical basis for primary acquired nasolacrimal duct obstruction. Arch. Ophthalmol., 115 (1): 71-74, 1997.

11- FRANCISCO F.C., CARVALHO A.C., FRANCISCO V.F., FRANCISCO M.C. and NETO G.T.: Evaluation of 1000 lacrimal ducts by dacryocystography. Br. J. Ophthalmol., 91 (1): 43-46, 2007.

12- KARPISHCHENKO S.A., VERESHCHAGINA O.E. and KARPOV A.A.: [Endoscopic septoplasty as a stage of endonasal dacryocystorhinostomy]. Vestn Otorinolaringol., 85 (6): 56-59, 2020.

13- KANG M.G., SHIM W.S., SHIN D.K., KIM J.Y., LEE J.E. and JUNG H.J.: A Systematic Review of Benefit of Silicone Intubation in Endoscopic Dacryocystorhinostomy Clin. Exp. Otorhinolaryngol. Jun., 11 (2): 81-88, 2018.

14- KNISELY A., HARVEY R. and SACKS R.: Long-term outcomes in endoscopic dacryocystorhinostomy. Curr. Opin. Otolaryngol. Head Neck Surg. Feb., 23 (1): 53-8, 2015.

15- REZAEIAN A., ABTAHI-FOROOSHANI M. and GHANBARI M.A.: Endoscopic dacryocystorhinostomy using mucosal flaps for bilateral overlapping. Am. J. Clin. Exp. Immunol. Jun., 15; 9 (3): 22-27, 2020.

16- SINGH A.P., NARULA V., MEHER R. and BRAZ J.: A new approach to endoscopic DCR. Otorhinolaryngol. Oct., 78 (5): 7-11, 2012.

17- VLADIMIR S. YAKOPSON, JOSEPH C. FLANAGAN, DANIEL AHN and BETSY P. LUO: Dacryocystorhinostomy: History, evolution and future directions, Saudi J. Ophthalmol. Jan., 25 (1): 37-49, 2011.

18- VARUN HARISH and ROSS S. BENGER: Origins of lacrimal surgery, and evolution of dacryocystorhinostomy to the present, Clinical and Experimental Ophthalmology, 42: 284-287 doi: 10.1111/ceo.12161, 2014.

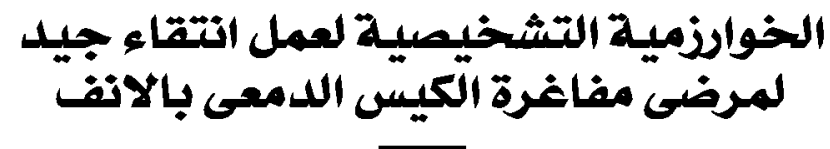

ان مرض الدماع ينتج عن انسداد جهاز التصريف الدمعى ابتداءا من النقطة الدمعية ثم القنية الدمعية ثم الحقيبة الدمعية ثم القناة الدمعية.

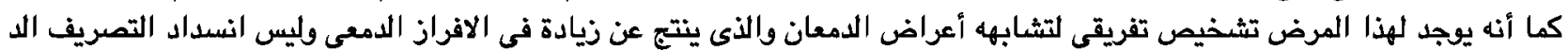

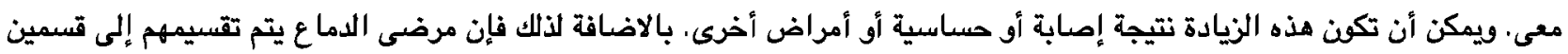

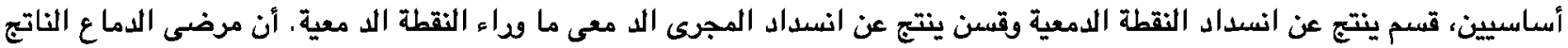

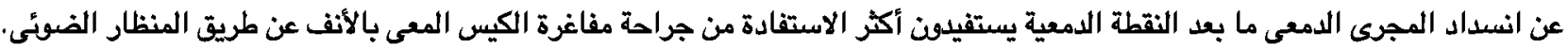

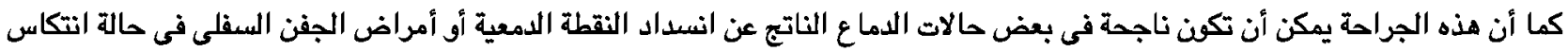

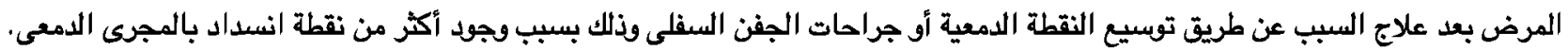

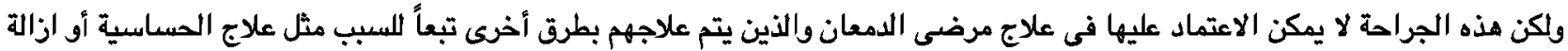

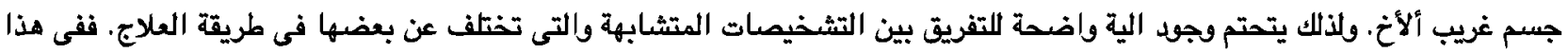

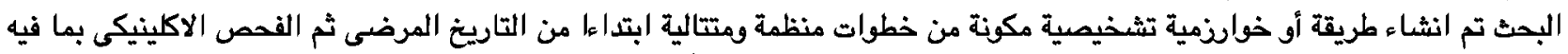
من استخدام الميكروبكوب الثقى و منظار الأنف وصبغة الفلويسين ثم أخيراً باستخدام وفى بعض الفئ الحالات عمل أشعة مقطعية على الجهاز

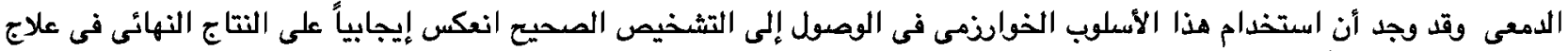
مرضى الدماع وأيضاً على علاج مرضى الدمعان عن طريق تجنب الجراحات الفير مناسبة. 